\title{
EINOGRAFIA ON E OFF-LINE: CIBERCAFÉS EM TRINIDAD
}

\author{
Daniel Miller \\ University College London - Reino Unido \\ Don Slater \\ London School of Economics and Political Science - Reino Unido
}

Resumo: O presente artigo questiona pressupostos sobre a distinção, comum na pesquisa de Internet, entre on-line e off-line. Várias pesquisas presumiram a "virtualidade", bem como uma forte divisão entre o on-line e o off-line como sendo um dado e um ponto de partida metodológico e analítico em pesquisa. Argumentamos que quando se aborda o uso de fato da Internet a partir de uma abordagem etnográfica, uma tal distinção se revela como um feito social altamente contingente: alguns atores empregam grandes habilidades para estabelecer uma distinção clara entre on-line e off-line em suas práticas de Internet; em outros, tal distinção não tem sentido, ou não é desejável, e tais distinções não são de fato estabelecidas. Utilizamos uma comparação entre cibercafés em Trinidad para demonstrar essa variabilidade e a ampla gama de diferentes relações on-line/off-line que são realmente observadas. Nós relacionamos esse material com a questão mais geral de se estabelecer "contextos" na pesquisa etnográfica.

Palavras-chave: cibercafés, etnografia, Internet, virtualidade.

Abstract: This article interrogates assumptions about the on-lineloff-line distinction in internet research. Much research has presumed "virtuality" and a strong division between the on-line and the off-line as a methodological and analytical given and starting point for research. We argue that when actual internet use is approached from an ethnographic perspective, this distinction turns out to be a highly contingent social accomplishment: some actors deploy great skill to establish a sharp on-line/off-line distinction in their internet practices; for others, it is meaningless or undesirable and the distinctions is not established in reality. A comparison of cybercafes in Trinidad is used to demonstrate this variability and the wide range of different on-lineloff-line relationships that are in fact observed. We relate this material to the overall issue of establishing "contexts" in ethnographic research.

Keywords: cybercafes, ethnography, internet, virtuality. 
O objetivo deste artigo é refletir sobre o que significou, na prática, o termo "etnografia" quando Daniel Miller, em co-autoria com Don Slater, estava realizando uma pesquisa para a elaboração de um livro intitulado The Internet - An Ethnographic Approach. ${ }^{1}$ Colocar o termo "etnografia" no título foi uma reflexão apropriada sobre sua centralidade na concepção do projeto, na forma com que ele foi desenvolvido e nas conclusões que foram formuladas. De várias formas, a etnografia foi ela própria tanto a premissa quanto a conclusão de nosso trabalho, assim como a Internet. Na primeira parte deste artigo, nós refletiremos sobre nossos problemas com esse termo. Nós, então, apresentaremos um estudo de caso que consiste na pesquisa que conduzimos sobre cibercafés e, na seção final, nós refletiremos sobre as formas com que uma abordagem etnográfica produz novas perspectivas sobre os conceitos pelos quais a Internet tem sido assimilada pela literatura acadêmica. Sobretudo, a etnografia como uma abordagem - algo mais do que somente um outro "método" - permite que se problematizem termoschave que foram assumidos por estudos anteriores sobre a Internet como se fossem propriedades da nova tecnologia, ao invés de feitos sociais de atores que reconfiguram tanto as tecnologias quanto seus "contextos", um em relação ao outro. Esses termos incluem as distinções entre on-line e offline, virtualidade e ciberespaço, cibercafés e, claro, a "Internet" ela própria.

\section{Etnografia on e off-line}

Nós dois [autores] nos reunimos, dentre outras coisas, por uma insatisfação comum com a literatura emergente sobre a Internet e um compromisso de tentar algo bastante diferente. Nós somos relativamente conservadores em nossa defesa dos cânones tradicionais da investigação etnográfica. Isso nos pareceu particularmente importante no presente momento, quando o termo "etnografia" tem se tornado algo da moda em muitas disciplinas. Em algumas áreas, como nos estudos culturais, o termo passou a significar simplesmente um distanciamento da pura análise textual (McGuigan, 1992). Em outros casos, a idéia de uma etnografia da Internet passou a indicar essencialmente que o estudo trata quase inteiramente de uma "comunidade" e relacionamentos on-line, como, por exemplo, nas "etnografias do ciberespaço". ${ }^{2}$

\footnotetext{
1 "A Internet - Uma Abordagem Etnográfica" (N. de T.).

2 Markham (1998), Paccagnella (1997); para uma discussão completa e reflexiva, ver Hine (2000).
}

Horizontes Antropológicos, Porto Alegre, ano 10, n. 21, p. 41-65, jan./jun. 2004 
Definir exatamente a natureza de nosso problema com o uso desse termo certamente seria difícil. Nos anos 90, um de nós (Daniel Miller) já havia publicado dois livros sobre Trinidad (Miller, 1994, 1998) que tinham como subtítulo "uma abordagem etnográfica", e uma coletânea de pesquisas de seus alunos pós-graduandos que especificamente advogava por uma abordagem etnográfica de estudos culturais materiais (Miller, 1998). Sua resposta inicial aos livros como o de Markham (1998) foi de que esses livros demonstraram que a etnografia não deveria ser meramente reduzida à experiência de estar on-line. Uma abordagem etnográfica da Internet deveria incluir seguramente pesquisas on-line e off-line.

Ficou imediatamente evidente que essa resposta era muito simplista, e o encontro com o trabalho de Slater o evidenciou. Entre nós, Don Slater havia recentemente completado um estudo de 18 meses baseado inteiramente em pesquisa on-line, e convergia com Miller $(1994,1998)$ ao considerar esta claramente uma etnografia (Slater, 1998). Entretanto uma questão persistia: se esse estudo não se distinguia de outros pela pesquisa off-line, o que justificava que o considerássemos como sendo um exemplo satisfatório de etnografia? Nos anos recentes, tem havido um número de críticas à definição convencional de etnografia que talvez nos ajudem a responder a esta questão (Clifford, 1997; Gupta; Ferguson, 1997; Marcus, 1995, 1998).

O primeiro nível de definição deve servir para excluir aqueles casos em que a maioria dos profissionais veria como constituindo um claro mau uso do termo. $\mathrm{Na}$ antropologia, os critérios primários da etnografia incluem a observação participante e o tempo passado na comunidade ou no espaço social estudado. $\mathrm{O}$ argumento que principalmente emerge nos conselhos que os orientadores dão aos seus alunos de pós-graduação é que esse período de tempo proporcionava a oportunidade para conhecer as pessoas e para estas se familiarizarem com a presença de um estranho. Nessa experiência não há nenhuma pretensão de que se estivesse alcançando algum estado puro de presença objetiva. Isso é visto, no entanto, como substancialmente diferente do relacionamento encontrado nas pesquisas que utilizam pesquisa quantitativa (com questionários e grupos focais). Na etnografia, o tempo de um ano é geralmente especificado como um período mínimo para o encontro na pesquisa de campo.

Nessa perspectiva percebi (Daniel Miller) que minha primeira pesquisa em Trinidad confirmava completamente esse requisito, já que quase todas as famílias que chegara a conhecer e me relacionar se modificaram com o 
tempo, mostrando-se bastante diferentes da forma como elas se apresentaram inicialmente. Uma observação participante extensa demarca claramente um relacionamento que é bastante distinto de usos recentes e mais frouxos do termo em vários ramos dos estudos culturais e da mídia, dentre outros. Em contraste, não somente com a análise textual, mas também com a entrevista e outros encontros com os outros a curto prazo e não contextualizados, a etnografia compreende um leque de canais metodológicos ou uma "triangulação" (Silverman, 1995) que permitem que emerjam não só conhecimentos mais profundos como também conhecimentos que não confirmam as observações iniciais. Isto foi crucial na etnografia on-line anterior de Slater: apesar da ausência de contato face a face, ela envolveu aquela triangulação de participação, observação, conversa, texto e, claro, relacionamentos que - sustentados ao longo do tempo - produziram inconsistências, por exemplo, entre discurso e comportamento, que se mostraram centrais para a análise final.

O segundo nível para definir a virtude da etnografia argumenta que, através de um período estendido de tempo e participação, os objetos e sujeitos de pesquisa podem ser vistos no âmbito de molduras ou contextos mais amplos. A etnografia oferece um conhecimento não só mais vasto como mais "holístico": nós podemos situar o fenômeno dentro do contexto mais amplo possível, de forma que cada um é usado metodologicamente para fazer sentido ao outro. Uma pesquisa sobre negócios, por exemplo, se aprofunda quando há suficiente conhecimento de fundo sobre etnicidade, gênero e classe, de forma que fique claro como tais "contextos" influenciam e se relacionam com os negócios em operação. É claro, a distinção entre "fenômeno" e "contexto" não corresponde diretamente àquela entre on-line e off-line, posto que depende do nível de análise que se tem e de como se define o "campo".

No meu primeiro trabalho (Don Slater), o cenário era uma pequena esfera de interação (troca de sexpics no Internet Relay Chat) dentro de um espaço comunicativo que era, ele próprio, uma pequena fração da atividade na Internet. "Colocar no contexto" poderia ser definido em termos de características mais amplas, mas ainda substancialmente on-line, dado que essa situação era o principal enfoque do estudo. Por outro lado importa considerar que se limitar à pesquisa on-line não necessariamente implica que contextos mais amplos se tornem invisíveis ao pesquisador. Era claramente possível - e, de fato, necessário - nessa pesquisa (de Slater) 
contextualizar o que foi observado em termos de aspectos como discursos sobre sexualidade, a estrutura normativa de instituições como a família, a distribuição de expertise tecnológica em termos de gênero, e assim por diante. Essas características poderiam ser abordadas tanto pela emergência em que foram observadas on-line quanto pelos conhecimentos de fundo. Em ambos os casos, a qualificação para ser considerada como uma etnografia não foi se se pesquisou especificamente contextos off-line, mas se se partiu do compromisso maior em relacionar o fenômeno a contextos mais amplos (independentemente de como foram definidos) ou se, ao invés, se começou de noções como "virtualidade" ou "ciberespaço", que envolvem uma pressuposição metodológica em que o cenário poderia ser tratado como sui generis, autocontido e autônomo.

A esta altura, nós poderíamos adicionar um número de outras características definidoras de uma etnografia, tanto da tradição antropológica quanto da sociológica, que ampliam as implicações do envolvimento em longo prazo, relacional e contextualizado de várias formas. A etnografia carrega um senso de observação in situ. Ela invoca um envolvimento hermenêutico que constitui um processo dialógico de aprendizado e compreensão cultural - como na famosa demanda de Clifford Geertz (1973) de que sejamos capazes de distinguir uma piscadela de um tique ao conseguirmos entender o que está sendo dito. $\mathrm{E}$ isso geralmente requer a pressuposição sobre a racionalidade, no sentido mais amplo, do que está se passando: de que o que as pessoas fazem tem sentido para elas e deve ter para nós. $\mathrm{O}$ ponto é que nenhum desses compromissos implica imediatamente uma posição específica sobre a questão da pesquisa on-line versus a pesquisa offline. Ao invés, demandam uma atenção reflexiva sobre como esses compromissos devem ser honrados em termos das questões, condições e "contextos" particulares da pesquisa.

Isso significa retornar à questão sobre o que exatamente nós podemos querer dizer com os contextos e as molduras da pesquisa etnográfica. Em anos recentes, escritores como Latour (1996) e Strathern (1999) têm questionado a separação da investigação em objetos e sujeitos, de um lado, e seus contextos, de outro, como se fossem entidades separadas, as quais o etnógrafo, como analista, reúne novamente de alguma forma. Por trás de suas críticas dos conceitos simples para contexto, Latour e Strathern vêem claramente que um efeito dessa separação é a reificação de algo chamado "sociedade", que é tido como o contexto do que estiver sendo estudado. Eles 
se opõem à idéia, por exemplo, de que alguém poderia ter um estudo sobre obras de arte onde a sociedade seja especificada como o contexto, ou um estudo das relações de classe onde a economia política é definida como o contexto. Assim, a crítica deles traz, de alguma forma, a antropologia social de volta a um alinhamento próximo ao estudo da cultura material, um ramo da antropologia que manteve um conceito de cultura como um processo que produziu tanto a materialidade quanto as relações sociais, sem que qualquer um fosse anterior ao outro (Miller, 1987). Todas essas abordagens sugerem que a etnografia deveria formar parte de um esforço para dissolver qualquer dualismo desse tipo e reconhecer que o relacionamento entre o fenômeno e seus contextos seja visto como recíproco, isto é, em qualquer pesquisa o que, de uma perspectiva, é o objeto de estudo A e o seu contexto B, poderia, de outra perspectiva, ter sido o objeto de estudo B e seu contexto A. Podemse estudar os carros em seu contexto social, mas pode-se igualmente estudar o tipo de sociedade que se desenvolve dentro de um meio cultural em que os carros têm um papel proeminente.

Deve ficar claro que o compromisso etnográfico de "colocar as coisas no contexto" precisa evitar o perigo de reificar o objeto tanto quanto evitar o perigo de produzir um contexto reificado analiticamente. Isso significa desagregar "a Internet" na profusão de processos, usos e "tecnologias" sociais que ela pode compor em diferentes relações sociais ao invés de considerá-la como um "objeto" único com propriedades inerentes que podem, no máximo, ser expressos de formas variadas em diferentes contextos. Novamente, esse assunto transcende a distinção entre on-line e off-line. Há uma enorme diferença entre começar uma etnografia on-line a partir da pressuposição de que a Internet forma inerentemente relacionamentos "virtuais" e pode, portanto, ser estudada como um cenário autocontido (ignorando os "contextos" off-line), em oposição a descobrir - no meio de uma etnografia - que algumas pessoas estão tratando essas mídias como se fossem virtuais e fazendo tudo ao seu alcance para separar seus relacionamentos on-line daqueles off-line (como foi, por vezes, o caso na pesquisa anterior de Slater, mas não foi absolutamente o caso no estudo de Trinidad). Diferentes circunscrições do objeto e do contexto surgem através dos seus inter-relacionamentos observados.

As etnografias que fazem argumentações a partir de posições como a de Latour (1996), Strathern (1999) ou dos estudos de cultura material opõem 
qualquer expectativa que nós objetivamos para estudar a apropriação social da tecnologia. O que nós, ao invés, buscamos é um estudo dos processos que têm, como suas conseqüências, a geração do fenômeno que nós observamos. No presente caso, nem a Internet é dada como uma tecnologia que é o objeto de estudo, nem Trinidad é separado como um contexto social ou cultural. Ao contrário, nós objetivamos examinar a Internet como um processo cultural trinitino, ${ }^{3}$ assim como entender como Trinidad pode agora ser, dentre outras coisas, um produto do uso da Internet.

Isso fornece a base para nossa posição consistente contra muito da literatura prévia sobre a Internet. O problema não é só a falta generalizada de envolvimento contextualizado e em longo prazo. Nem é simplesmente a fascinação com o "virtual" e o "ciberespaço", que tem levado tantos pesquisadores a conduzir estudos inteiramente on-line sobre os modos de interação e relacionamento específicos ao cenário on-line. O problema, ao contrário, é a falta de atenção às formas em que o objeto e o contexto precisam ser definidos em relação um ao outro para projetos etnográficos específicos. Às vezes, o uso da Internet parece constituir virtualidades, às vezes não. Certamente, no entanto, as diferenças observadas sobre esse assunto irão ou deveriam mudar as formas como um(a) pesquisador(a) reflete sobre a complexa relação entre pesquisa on-line e off-line, ao invés de incitá-lo(a) a começar de uma posição presumida e dogmática sobre esse tema.

Apesar da pesquisa anterior de Slater, que abordou a troca de materiais sexualmente explícitos (sexpics) no Internet Relay Chat (IRC), ter sido conduzida inteiramente on-line, esta teve que prestar atenção constante à relação entre atividades on-line e off-line e, acima de tudo, em como os próprios participantes construíram distinções altamente diversas, complexas e fluidas entre suas vidas on-line e off-line. Por exemplo, para entender o que algumas donas-de-casa norte-americanas estavam fazendo quando elas gastam horas envolvidas nessa troca de sexpics é necessária a compreensão de seus relacionamentos off-line, em geral com seus parceiros. Isto, por sua vez, explica um dos mais surpreendentes resultados que foi que, ao invés de serem uma vanguarda libertária, muitas daquelas envolvidas têm visões

\footnotetext{
Segundo o dicionário Houaiss, "trinitino" é um termo "relativo a ou o que é natural ou habitante da República de Trinidad e Tobago, país situado a sudeste da América Central, no mar o Caribe" (p. 2769). Podem ser usados também "trinitário" ou "trinitário-tobagense". Aqui optou-se por "trinitino", pois o artigo se refere à pesquisa realizada na ilha de Trinidad somente (N. de T.).
}

Horizontes Antropológicos, Porto Alegre, ano 10, n. 21, p. 41-65, jan./jun. 2004 
estreitas e, por vezes, bastante conservadoras sobre a moralidade da atividade na qual estão envolvidas. Por exemplo, elas podem ficar bastante chateadas com aqueles que fraudam a quantidade de trocas que foram combinadas (Slater, 2000) ou que trocam fotos que são consideradas como além de suas convenções como sexpics apropriados ou moralmente justificados. Em síntese, este não é um estudo em que há simplesmente um fenômeno - a troca on-line de sexpics, do qual o off-line é o contexto que o explica. Ao invés disso, há um reconhecimento do relacionamento complexo e nuançado entre os mundos on-line e off-line que produz as estruturas normativas desses dois mundos.

Além disso, tal estudo se recusa a separar a Internet, como uma tecnologia, do processo de troca. A maior parte dos primeiros estudos sobre a Internet via certas propriedades como intrínsecas a esta nova mídia. Mais importante, eles a proclamaram como o meio para o desenvolvimento do virtual. De fato, foram precisamente as áreas, como a troca de sexpics, com uma recompensa aparente sobre a fantasia e o anonimato, assim como uma nova relação libertária e performativa à identidade pessoal, que foram proclamadas como evidência desta base técnica para o novo mundo da virtualidade. A pesquisa de Slater certamente oferece muita evidência para onde e quando o virtual se desenvolve como uma característica do uso da Internet. Mas, ao mesmo tempo, a pesquisa mostra que isso não é alguma propriedade intrínseca da tecnologia. Essa crítica da virtualidade iria se tornar central para o trabalho subseqüente sobre Trinidad (Miller; Slater, 2000, cap. 1).

Portanto, ao colocar nosso compromisso de desenvolver uma etnografia em Trinidad, nós começamos com um pacto comum de trabalhar tanto online quanto off-line, mas não com base numa premissa simplista ou dogmática de que nenhuma pesquisa conduzida totalmente on-line poderia contar como uma etnografia adequada. Antes, foi com uma mente voltada para as implicações mais profundas que buscamos relacionar os mundos online e off-line, sem ver qualquer um como o contexto do outro. Não seria um estudo da tecnologia em um contexto social, mas um estudo na formação de formas culturais normativas e transientes que dissolveram dualismos simples de sujeitos e objetos. O ideal é que a Internet "trinitina" poderia ser entendida como um produto do próprio Trinidad, justamente como a cultura 
contemporânea de Trinidad está se tornando um produto, dentre outras coisas, de seu relacionamento com a Internet.

Ademais, o uso do termo geral "Trinidad" só poderia ser garantido onde ele era um produto do encontro etnográfico. A teoria e a moda antropológicas atuais têm sido crescentemente céticas sobre o uso de tal termo, sob a alegação de que ele ignora a diversidade dos povos e de que ele reproduz o discurso nacionalista. Mas nós não poderíamos mais assumir que usar tal termo era agora uma coisa "imprópria", mas ultrapassávamos tal constrangimento ao assumir que nós poderíamos e deveríamos usar o termo onde ele claramente ofuscou aquelas diferenças e a diversidade que eram salientes à nossa investigação. De fato, uma conclusão central de nossa pesquisa foi que, longe de dissipar um senso de identidade nacional através da exposição à mídia global, a Internet se transformou em um meio primário para refinar um gênero de ser especificamente nacional (Miller; Slater, 2000, cap. 4). Nós dois podemos estar aflitos por tal nacionalismo, mas vemos nossa tarefa como a de compreendê-lo e não fingir que ele não existe. Para nós, o ponto das críticas aos rótulos nacionais, ou mesmo da própria cultura mundial, é forçar os etnógrafos a discriminar no seu uso tais termos e aplicá-los somente onde forem claramente salientes, não determinar a priori o que nós queremos ou "precisamos" encontrar no campo.

O objetivo geral (e talvez ambicioso) de nossa pesquisa em Trinidad era holístico no sentido etnográfico mais clássico: nós quisemos fazer sentido de um fenômeno complexo ("a Internet”) em relação a uma cultura complexa e não homogênea ("Trinidad"), e sabíamos que isso iria envolver olhar para uma enorme diversidade de usos, objetos e relacionamentos sociais. De um extremo, olhar para "objeto" e "contexto" significou, por exemplo, considerar usos específicos da mídia em relação à construção material da infra-estrutura das telecomunicações e das práticas de negócios: isto quer dizer, um envolvimento distintamente off-line com a economia política. De outro extremo, nós estávamos envolvidos com reconstruções um tanto fenomenológicas da experiência de jovens trinitinos ao representar música para outros que estavam on-line nas salas de chat do ICQ. Qualquer um dos extremos serviria como estudos plenos em si mesmos, com mudanças correspondentes no que efetiva uma etnografia. Em nossa própria pesquisa, o assunto era como reunir esses diferentes enquadramentos dentro de uma história maior. 
De fato, muito da nossa pesquisa foi realizada on-line, envolvendo uns 15 meses de coleta e análise de dados da Internet, como páginas, extensa correspondência por e-mail e participação em chats e ICQ, que poderiam ser mantidas ao longo do tempo como relacionamentos on-line. Alguns de nossos informantes mantiveram-se em contato para isso por 15 meses. Além disso, havia o trabalho off-line envolvido em entrevistar trinitinos em Londres e Nova Iorque. Estas entrevistas variaram de individuais a entrevistas que se basearam nos relacionamentos que haviam sido estabelecidos on-line a conversas com amigos de Miller que poderiam dialogar sobre o papel da Internet em suas conexões com Trinidad. Finalmente, cada um de nós passou um mês em Trinidad, onde pudemos conduzir entrevistas com uma variedade de usuários (individuais, de negócios, do governo, da educação). Nós também pudemos conduzir um survey de porta em porta (seguido de entrevistas selecionadas e aprofundadas) em quatro áreas previamente estudadas por Miller; permitindo, assim, tanto a análise quanto o envolvimento comparativo com ambos, usuários e não-usuários de novas mídias. De forma mais significativa, nós pudemos colocar nossa pesquisa no contexto de envolvimento e contatos com a ilha, estabelecidos por Miller a longo prazo, e, assim, atingir a atividade etnográfica já em andamento. Depois, os cibercafés - o assunto do resto deste artigo - ofereceram um espaço importante de pesquisa, em vários sentidos. Como espaços públicos cheios de usuários altamente motivados e mais casuais, eles eram espaços muito frutíferos para socializar, ${ }^{4}$ constituindo tanto locais significativos de uso da Internet em si mesmos, mas também nos oferecendo acesso a um uso mais geral da Internet através de observação e de entrevistas. Finalmente, os donos e os trabalhadores (em geral, não-oficiais) dos cibercafés apresentaram-se como conhecedores em potencial desse fenômeno.

O que nós definitivamente não queremos sugerir, no entanto, é que os cibercafés, de alguma forma, fizeram a "Internet em Trinidad" mais fácil ou fisicamente visível para nós como observadores do que qualquer outro espaço de pesquisa, ou que eles ofereceram uma definição auto-evidente de objeto e contexto, um lugar óbvio para observar a conjuntura do on-line e do off-line ou de "contextualizar a Internet". O eixo de nossa reflexão se

\footnotetext{
4 Aqui (e adiante) "socializar" substitui, de forma não exatamente equivalente, a expressão, bastante própria da língua inglesa, to hang out. (N. de T.).
}

Horizontes Antropológicos, Porto Alegre, ano 10, n. 21, p. 41-65, jan./jun. 2004 
apóia no exemplo dos cibercafés para problematizar o que esses termos significam no contexto do encontro etnográfico.

Por fim, este trabalho claramente se enquadra dentro da resposta contemporânea a um conjunto mais flexível de encontros que problematizaram o conceito mais tradicional de campo (Gupta; Ferguson, 1997; Marcus, 1995), em geral, e com respeito à Internet, em particular (Hakken, 1999, p. 58-60). Nós esperamos, assim, que ele empregue as novas possibilidades que a Internet oferece para a condução de pesquisa etnográfica, enquanto evita o que nós veríamos como tentações perigosas para encurtar e constranger aquela perspectiva.

\section{0 que é um cibercafé em Irinidad?}

O uso global do termo "cibercafé" é diverso, como Rao (1999) já havia notado. Em Trininad, os cibercafés eram empresas muito instáveis e, na maior parte dos casos, não lucrativas. Geralmente consistiam em adjacências de outros negócios (venda ou manutenção de computadores, cursos particulares de tecnologia da informação) ou estavam no limite de se transformarem em outro negócio (webdesign e tecnologias de Internet). Eles também variavam de fraudes a centros comunitários dinâmicos. É bem provável que o cibercafé como uma instituição represente uma fase particular no desenvolvimento do uso da Internet em Trinidad. Certamente, o dono de um dos mais antigos e bem sucedidos desses cafés sentia que ele tinha somente dois ou três anos de viabilidade antes que o grau de computadores domésticos on-line lhe tirasse o negócio. Havia muitas histórias de cibercafés que tinham ido e vindo, especialmente na capital, Port of Spain, que sugeriam que a maioria de tais empreendimentos tinha se provado não lucrativa em qualquer etapa. Porém, nós pudemos localizar seis cibercafés em operação que, em si mesmos, demonstraram uma considerável diversidade, e cada um deles ofereceu insights adicionais no potencial para tal empreendimento.

A diversidade coloca um problema para o estudo dessas instituições, exacerbado pelo fato de que nem tudo que poderia ser considerado como um cibercafé usava esse nome, e alguns que o usavam talvez não devessem fazê-lo. Um etnógrafo trabalhando numa sociedade relativamente autônoma geralmente tenta definir os objetos de análise através da semântica local e 
das diferenças significativas das práticas. No caso dos cibercafés, no entanto, tanto o conceito quanto a prática parecem ser importações recentes, requerendo o conhecimento sobre o significado do conceito no discurso global da Internet. De fato, um negócio trinitino requisitar o título de "cibercafé" era também assumir um significante da modernidade global e da cultura de ponta. Mas isso, é claro, já implora por múltiplas questões etnográficas: como tais termos e práticas, como "cibercafé", podem assumir novos significados em um lugar como Trinidad.

Nós oferecemos quatro exemplos de espaços de Internet que plausivelmente se relacionam à noção de cibercafé. $\mathrm{O}$ que os conecta não é tanto o nome (o qual alguns não requisitam e outros usam como um significante vazio), mas sim o fato de colocarem o acesso à Internet no espaço público. Essa publicização é também usualmente associada a duas outras características: sociabilidade e processos educacionais (formais ou informais). Nós comentaremos sobre o papel da publicização em Trinidad na conclusão desta seção.

Tome-se como primeiro exemplo o cibercafé que nós encontramos na principal rua de uma cidade na parte central de Trinidad. Certamente, ele empregava as pretensões de linguagem e de apresentação de um cibercafé internacional; além disso, ele admitia (como fazia a maior parte dos cibercafés em Trinidad) ensinar os requisitos para o uso de computador e Internet. Mas o que de fato acontece lá? Os primeiros sinais preocupantes são aqueles pregados nas paredes, que revelam que os donos cobram valores exorbitantes para mandar e-mails individuais. O segundo sinal foi a imagem deprimente de uma senhora mais velha, claramente tradicional das Índias Orientais, sentada na frente de um computador por horas a fio, usando um dos programas mais vazios de software gratuito que se pretendeu a ensinar o uso de um computador. Não ajudava também que o dono, claramente relutante em nos encontrar, tinha todos as características estereotipadas de um "malandro" ou outros rótulos para comerciantes dúbios de mercadorias ambíguas. Em síntese, logo ficou claro que o termo "cibercafé" constituía a fachada para uma fraude. O mesmo discurso global que assume que um país moderno deve ter coisas chamadas cibercafés também poderia ser explorado para extrair dinheiro de vítimas vulneráveis. Nós também entrevistamos a mulher que de fato conduzia os treinamentos: seu jeito

5 Aqui "malandro" substitui o termo spiv (N. de T.).

Horizontes Antropológicos, Porto Alegre, ano 10, n. 21, p. 41-65, jan./jun. 2004 
evasivo com respeito ao que eles faziam, assim como sua intenção declarada de expandir o "treinamento" às escolas primárias, deixou claro que a principal preocupação era localizar grupos novos e até mais vulneráveis para explorar no futuro.

Em completo contraste, nós nos voltamos para o lugar em que passamos considerável quantidade de tempo "socializando" durante nosso período de permanência em Trinidad, mas que não se chamava de cibercafé. Consistia em uma pequena loja, estilo birosca, perto da principal rodoviária na capital do país, mantida por um dos amigos mais próximos de Miller. Apesar da loja não ter nenhuma conexão com computação, o dono havia - de forma típica para os trinitinos - investido em uma máquina "estado da arte", equipada com scanner e modem, apesar do pequeno espaço que agora a loja dominava e do fato que ele claramente não deveria ter retirado o empréstimo necessário de seu orçamento precário. $\mathrm{O}$ indivíduo em questão sempre teve uma presença pública como um conselheiro local, um organizador de eventos esportivos, um representante das preocupações das pessoas locais e, em geral, como uma fonte de serviço e aconselhamento enormemente generosa e amigável. Como resultado, a maioria das pessoas que vinha e usualmente ficava por algum tempo na loja não eram de fato fregueses, mas amigos e pessoas que haviam sido recomendadas para vir por todo tipo de razão. A loja em si gerava um orçamento mínimo. Uma das razões que nos fazia tender a ficar por ali, além de apreciar a companhia, era que mais e mais pessoas vinham para usar ou procurar dicas sobre o uso de computadores. Tipicamente, um senhor mais velho gostaria de enviar um e-mail e solicitava esclarecimentos sobre se faria diferença o indivíduo com o qual ele estava contatando estar "lá" ou não quando o e-mail chegasse. Por sua vez, outras pessoas vinham e ajudavam o dono a aprender sobre o potencial de sua própria máquina. Como muitos trinitinos, ele via a loja simplesmente como um plano dentre um conjunto de "planos" potenciais que agora incluíam a idéia de organizar uma troca on-line de empregos para pessoas trabalhando em barcos, ou como um lugar para se transformar fotografias pessoais em cartões de egreetings. Dinheiro algum era pago nem ao dono, pelo uso de seu equipamento de e-mail, nem do dono, pela ajuda que recebia para usar a máquina, mas, claramente, como um lugar de interação social, que mais e mais girava entorno do uso da Internet, alguma coisa semelhante a um cibercafé estava se desenvolvendo. 
O terceiro exemplo se refere a um dos cafés mais famosos da capital do país, mas que havia sido fechado algum tempo antes de nossa visita. Este havia sido um negócio bastante elaborado, com muitas estratégias decorativas, incluindo uma cascata com água no canto da parede, um grande leque de máquinas e uma clientela em desenvolvimento. Entre outras considerações, nós ouvimos que, na época do Natal, foram os clientes regulares tanto quanto a equipe que haviam ajudado a dar ao lugar sua decoração festiva. Do ponto de vista do cliente, a loja era muito bem sucedida e um bom exemplo do ideal de cibercafé. Da perspectiva do seu dono, no entanto, o cibercafé era mais uma frente para o negócio principal: venda e manutenção de computadores. $\mathrm{O}$ investimento era intencionado para ser uma chamada, um tipo de chamariz que iria trazer clientes para um negócio muito mais lucrativo. Entretanto, o cibercafé enquanto negócio fora avaliado como ineficiente para o aumento dos lucros desejados, enquanto que outros negócios poderiam promovê-los de forma mais eficaz. Dessa maneira justificavam os donos que, apesar de seu sucesso do ponto de vista dos usuários, o cibercafé se consistira em um fracasso, e conseqüentemente foi preciso fechá-lo.

Como nosso último exemplo, consideramos nossa pesquisa na biblioteca pública central. Esta está procurando expandir o uso da Internet e o acesso à informação colocando computadores on-line dentro das bibliotecas públicas. No momento, são apenas umas concorrências limitadas aos cibercafés particulares, já que há limitações consideráveis impostas ao seu uso (eles não podem ser usados para acessar o e-mail particular, e baixar ou imprimir arquivos está proibido). Como Liff, Steward e Watts $(1999,2002)$ mostram, as bibliotecas públicas têm algumas dificuldades em estabelecer esses espaços de sociabilidade dentro de seus domínios silenciosos e ordenados. O seu principal propósito era a obtenção de informações, por exemplo, para as crianças da escola fazerem seus projetos. Apesar de não terem o mesmo escopo de sociabilidade entre os usuários, como é encontrado nos cibercafés particulares, elas já estavam tendo bastante impacto e, em nossos surveys e contatos mais informais, o uso de computadores em bibliotecas públicas aparecia nas conversas tanto quanto os cibercafés particulares, talvez porque nós concentramos grande parte de nosso trabalho nas áreas mais pobres da população, onde o acesso gratuito era particularmente importante. 
Esses quatro exemplos de (demanda pelo) acesso público, sociável e educativo da Internet também devem ser entendidos dentro dos termos da relação entre os espaços públicos e privados de Trinidad. Nesse sentido, pesquisar os cibercafés em sociedades industrializadas ao norte coloca-os em severo contraste com o uso privado e doméstico, por um lado, e com o uso público nos negócios/trabalho, por outro lado. A sociabilidade trinitina freqüentemente atravessa esses espaços, o que, no caso do uso da Internet, confunde ainda mais o lugar e o significado possíveis para um "cibercafé". Nós precisamos posicionar essa palavra e esse conceito ao lado da professora local que permite a todas as crianças de sua rua mandarem e-mails e fazerem suas pesquisas escolares de seu computador particular, em um cenário altamente convivial. Nós também precisamos posicioná-los ao lado da profusão de pessoas que nos contaram que elas mandavam e-mails através de pessoas que tinham acesso nos seus locais de trabalho (e a maior parte dos empregadores trinitinos com quem conversamos tinha uma política bastante liberal em deixar que os empregados usassem o acesso do escritório para correspondências particulares).

A conclusão é que o cibercafé não é algo cuja definição e cujo significado podem ser derivados do mero fato de que aqui ele é importado. Em cada caso há considerável ambigüidade se nós devemos descrever o que nós estudamos como cibercafés. Ao invés, agora que nós nos voltamos para os exemplos mais óbvios dos cibercafés "clássicos", nós podemos ver que estes só podem existir em relação aos vários fatores que lhes conferem seus significados particulares nesse contexto.

\section{Dois cibercafés "clássicos"}

Uma coisa que parece abundantemente clara é que nenhum dos pontos sobre o acesso público a Internet, descritos acima, pode ser tratado simplesmente como espaço para observar o uso da Internet em um espaço público. Mais ainda, que o uso permitido ou habilitado em cada caso depende da forma específica da instituição e seu domínio sobre a Internet. Ademais, a forma de cada uma dessas instituições sempre dependeu do lugar de operação do seu "cibercafé" dentro dos objetivos e operações mais amplos da instituição (sendo uma biblioteca, um negócio, um professor). Talvez, de forma mais surpreendente, isso era igualmente verdadeiro nos dois 
cibercafés onde nós passamos a maior parte do nosso tempo, e que não somente se rotulavam explicitamente como "cibercafés", mas se conformavam à maioria das convenções norte-americanas ou européias: acesso pago em um número razoável de computadores on-line em um espaço público com suporte técnico e alguma facilidade para uma sociabilidade mais ampla.

O primeiro café (vamos chamá-los de "Limers") está localizado num cruzamento de uma rua movimentada em uma cidade provinciana. Ele fica no andar de cima de um estabelecimento alimentar que é parte do mesmo negócio, já que comidas e bebidas podem ser consumidas no conjunto de mesas que ocupam grande parte do espaço dentro do cibercafé. Ele tem uma forte ênfase na ambiência informal e convivial. Sempre há música, conversas barulhentas e intensa atividade. Os computadores são posicionados em torno das beiradas de três paredes, formando um crescente de oito máquinas. O resultado dessa disposição é que qualquer um que estiver sentado às mesas extras no centro tem, ao menos, uma vaga idéia do que está acontecendo em qualquer um dos computadores ocupados. Há uma forte ênfase na ambiência, com paredes pintadas e decoradas com figuras e pôsteres - por exemplo, sobre informações gratuitas disponíveis on-line. Uma música está sempre tocando ao fundo e vários dos punters têm opiniões firmes sobre esta questão, negociada com os donos. Os patrões são encorajados a lime, isto é, socializar pelas mesas, assim como de fato ficar on-line e muitos, se não todos os usuários, parecem vir com amigos ou parentes com o objetivo de interagir e ficar algum tempo pelas mesas centrais, assim como on-line.

Ao menos um dos casais de proprietários do café está geralmente presente, mas também o estão outros que são tanto formalmente empregados ou informalmente associados a eles, e que estão ocupados atualizando os componentes ou ajudando a resolver problemas com o sistema. Muitos dos usuários mais jovens observaram a importância da ajuda que eles recebem dos donos e está claro, em alguns casos, que isso suplanta os exíguos requisitos para usar os computadores, já que eles se referem a um deles como um tipo de "figura paterna" e comentam sobre as brincadeiras e a ajuda, que estabelecem a relação próxima que têm com ele. Isso reflete a personalidade e as fortes crenças do casal dono do café, que calmamente

6 Lime é uma gíria que significa algo como "socializar". Limers, portanto, seriam "aqueles que socializam" (N. de T.).

Horizontes Antropológicos, Porto Alegre, ano 10, n. 21, p. 41-65, jan./jun. 2004 
dá conselhos, apoio e encorajamento, assim como mantém tanto a ordem quanto o entusiasmo. Como notado por Liff, Steward e Watts (1999), trabalhando no Reino Unido, mas com material comparativo nos EUA e na Finlândia, os cibercafés parecem ser mais inclusivos e atrativos para novos usuários do que a maioria dos outros espaços para uso de Internet.

Da observação, das entrevistas com trabalhadores e usuários e da inspeção de "histórias" de uso anterior "logado" aos browsers, emerge um padrão muito claro de uso corriqueiro. O uso mais intenso é de e-mail, com muitas pessoas passando pelo local regularmente para checar suas mensagens, no caminho para casa de volta da escola ou do trabalho. Eles podem, então, participar dos seguintes usos mais populares: enviar egreetings e conversar em chats. A navegação é dominada pelas páginas de entretenimento populares, como a da MTV, mas também pessoas procurando por informações sobre faculdades norte-americanas. Grande número de estudantes e de jovens aparecem, geralmente em grupos, encorajados pelo marketing do café (seu slogan é: "Não apenas navegue... lime! - isto é, "socialize"); no entanto, há trabalhadores de vários tipos que vêm com um senso muito mais pragmático do que simplesmente ver um site específico ou checar seus e-mails, e depois partem com pouco interesse pela sociabilidade maior.

No entanto, esta fotografia não capta o sentido mais amplo do lugar. A "figura paterna", referida acima, - vamos chamá-lo de Andrew - combina um senso de responsabilidade comunitária e de empreendimento que caracterizava muito a vida trinitina e suas relações com a Internet. Andrew reuniu em torno de si múltiplos jovens rapazes entusiasmados e geralmente muito hábeis, que aprenderam com ele e um com o outro não só como manejar todos os aspectos de acesso e networking, mas avidamente se estendiam para outras áreas relacionadas, como webdesign, computação gráfica e animação. Por exemplo, enquanto estávamos lá, um grupo estava usando tecnologias de ponta na Internet (os últimos aplicativos de Shockwave) para produzir spots de propaganda de 30 segundos que depois eles transferiram para o vídeo para transmitir. O senso de Andrew e dos outros sobre no que o projeto como um todo iria se desenvolver e para onde estava indo mudava dia após dia (webdesign, publicidade na Internet, abrir novas filiais em outras cidades), mas estava sempre contido dentro de um compromisso confiante de aproveitar o talento abundante (e completamente sem treino) 
que rotineiramente entrava pelas portas do café. Andrew era uma espécie de empreendedor populista, uma postura igualmente expressada pelo desdém de sua equipe pela Microsoft e por outros gigantes que, eles sentiam, mantinham de forma ilegítima o total controle sobre um domínio em que o "pequeno negócio" poderia claramente fazer muito melhor.

O lugar do cibercafé, dentro de um propósito mais amplo, também levou a uma confusão entre funcionários e clientes. Isso não é incomum em cibercafés pelo mundo, onde jovens clientes entusiasmados assumem posições de responsabilidade remuneradas ou informais. No entanto, nesse caso, isso era claramente compreendido como parte do complexo relacionamento do negócio com a comunidade, de fato à noção de Trinidad tanto quanto à de vizinhança local.

Em contraste, um segundo cibercafé (vamos chamá-lo de "Chatters"”), também em uma cidade provinciana, é tomado pelo uso do mesmo espaço para o ensino de cursos de computação. O negócio central é a venda, reparo e manutenção de computadores, ao qual foram adicionadas três salas cheias com 12 ou mais computadores que são usados para um programa extensivo, bem planejado e sério de cursos de computação. Quando não em uso nas aulas, estes computadores podem ser usados para o acesso generalizado e pago pelos membros do "café". Esse é um típico espaço de negócios, com paredes brancas e sem decoração. De fato, não há áreas especificamente destinadas para socializar em geral, e o consumo de comidas e bebidas é proibido; porém, há uma ampla sala para socializar, que não é de forma alguma desencorajada. De fato, a ambiência social é muito amistosa e muito do uso de Internet é público, coletivo e convivial. Leva-se um ou dois minutos para perceber que um grupo em volta de uma bancada de computadores está em plena aula, ao invés de ser um bando de usuários do "café". Mais importante, porque o espaço é dividido em várias salas diferentes há mais privacidade tanto para os indivíduos quanto para os grupos se reunirem longe da multidão geral. Apesar dos donos e dos gerentes raramente serem visto no local, este é mantido como escola e cibercafé por um núcleo de jovens muito amigos entre si, que também ensinam e são ajudados pelos seus parentes ou por alguns usuários regulares, de novo confundindo a fronteira entre funcionários e clientes. A equipe é entusiasta, hábil e ambiciosa, mas,

7 Aqui, chatters seriam aqueles que falam, conversam, dialogam freqüentemente em um chat (N. de T.).

Horizontes Antropológicos, Porto Alegre, ano 10, n. 21, p. 41-65, jan./jun. 2004 
nesse caso, os ajudantes não remunerados estão mais interessados em expandir seu uso da Internet do que em desenvolver um projeto mais amplo; eles não se interessam, por exemplo, pelo aumento dos negócios do dono do café. A equipe faz trabalho de webdesign, mas isso é bastante separado de seu envolvimento no café.

$\mathrm{O}$ uso da Internet por esses usuários regulares era excepcionalmente dominado por relacionamentos, em chats e por e-mail, com pessoas no exterior, incluindo um grande número de envolvimentos românticos intensos via Internet. Como será discutido na seção seguinte, a sociabilidade do local era, assim, colorida por uma freqüente e intensa mistura dos relacionamentos on-line e off-line, e todo o lugar, por vezes, tomava a aura de uma novela em que os variados relacionamentos on-line e off-line daqueles envolvidos podiam ser dissecados e comparados. Eram as duas dúzias de usuários regulares que dominaram o que podia ser a estrutura de várias centenas de pessoas na região, que podiam passar pelo local para o uso ocasional. A maior parte daqueles visitantes usava o espaço como indivíduos, sem muita conexão aparente com os cafés como instituições além de achá-los mais ou menos agradáveis. Isso incluía pessoas que passavam para checar seus $e$ mails ou pesquisar um assunto especifico ou somente "navegar" ou conversar no chat por um tempo. A população era principalmente, mas não exclusivamente, jovem. Eles se remetiam à equipe principalmente para apoio técnico e ajuda no uso do software.

\section{On-line e off-line em cibercafés}

Parece claro, então, não só que os cibercafés podem significar coisas radicalmente diferentes, mas também que diferentes usos da Internet emergiram em cenários diferentes e, inversamente, que diferentes cenários se desenvolveram em torno de diferentes usos e constituições. "Uso" e "contexto" representam termos radicalmente diversos e inter-relacionados que demandaram uma atenção etnográfica minuciosa. O mesmo se aplica ao observar a distinção entre off-line e on-line que apareceu na nossa introdução: a etnografia não pode ser definida por essa distinção, mas esta certamente precisa ser empregada para que aquela possa ser estudada.

Primeiro, a relação entre off-line e on-line nos cibercafés era bastante variável. Em um extremo, os adolescentes socializando no Limers com uma 
namorada ou um namorado talvez nem cheguem perto dos computadores; a associação desse espaço com o mundo on-line talvez não signifique para eles mais do um local na moda para socializar. De forma contrária, a grande maioria do uso é provavelmente a checagem corriqueira de e-mails com um grau mínimo de sociabilidade ou mesmo de contato com a equipe, e nesse caso não faria uma grande diferença para as pessoas se elas estivessem acessando a Internet de casa, do trabalho ou do café.

No outro extremo - e o Chatters representaria bem este caso - há uma mistura complexa de on-line e off-line. Por exemplo, usuários-chave e membros da equipe desenvolveram extensas redes on-line de amigos, geralmente objetificados em suas listas de nicks (apelidos usados nos aplicativos de chats de tipo "I seek you"8) do ICQ, isto é, aquelas pessoas cuja presença on-line, no momento, seria comunicada quando o indivíduo com essa lista de apelidos ligasse sua própria máquina. Este era, portanto, o grupo de pessoas que estavam, no momento, disponíveis no chat. $\mathrm{Na}$ maior parte dos casos, tais usuários também estavam envolvidos em relacionamentos on-line que poderiam ser amizades relativamente fugazes, mas também incluía "namoros" on-line, com uma gama de possibilidades de compromisso e intensidade tão grande quanto se encontra em namoros offline. Não é uma surpresa que essas redes on-line estavam integradas com redes off-line. Por exemplo, um rapaz, que viesse sendo bastante bem sucedido no desenvolvimento de relacionamentos com mulheres on-line, talvez fosse solidário com seu amigo que havia tido muito menos sucesso. Ele talvez pedisse à sua namorada on-line, vivendo em Melbourne, Austrália, ou Seattle, nos EUA, para encontrar uma potencial namorada on-line para esse amigo. Ademais, o amigo em questão que ele estivesse ajudando podia ser seu vizinho de porta. Mas poderia ser, igualmente, um amigo online que ele jamais conhecera, mas que ele sabia, pelas conversas diárias, que não estava tendo muito sucesso nas tentativas cada vez mais desesperadas de "emplacar" on-line com as garotas.

Nós já tínhamos encontrado esse fenômeno antes de irmos para Trinidad, já que o funcionamento de tais redes sociais poderia ser traçado nos websites pessoais de trinitinos. Era muito comum, para um adolescente

\footnotetext{
8 Há aqui um jogo de palavras impossível de ser traduzido: I seek you (expressão que tem o mesmo som da pronúncia das letras ICQ) pode ser traduzido como "eu procuro você", que é justamente um dos objetivos principais de quem usa o programa ICQ (N. de T.).
}

Horizontes Antropológicos, Porto Alegre, ano 10, n. 21, p. 41-65, jan./jun. 2004 
com seu próprio website, listar, em contrapartida, seus amigos próximos nesse site, freqüentemente, com um link direto para suas páginas pessoais. Em parte, essa era uma maneira de deixar uma pessoa que estivesse "navegando" saber sobre o círculo de amigos do qual eles sentiam fazer parte, e que era freqüentemente referido por termos trinitinos comuns, como o possé ou o lime. Mas isso era mais do que somente um ato de referência. Os visitantes, por sua vez, seriam encorajados a fazer amizade com esses amigos, assinando seus livros de visitas, mandando-lhes e-mails ou admitindo seus nicks do ICQ. Uma vez mais, esses amigos poderiam ser pessoas que eram relacionadas off-line, mas eles também poderiam incluir amigos que eram conhecidos apenas on-line.

Se as amizades on-line pudessem, com efeito, ser trocadas como presentes entre amigos on-line e off-line, então o cibercafé poderia, ele mesmo, se tornar também um espaço para o desenvolvimento de novas configurações de amizades off-line baseadas no compartilhar de experiências on-line. Um dos casos mais claros da Internet sendo usada para ajudar a constituir uma forma de sociabilidade trinitina é o uso feito pelos gays trinitinos. Em sua visita anterior a Trinidad, Miller ficou impressionado pelo alto grau de homofobia entre a população trinitina em geral. Isto era evidente não só nas piadas e nas invectivas constantes nos jornais semanais. Indivíduos na comunidade de negócios, com quem ele havia trabalhado, viam a perseguição e o espancamento de homossexuais masculinos nas ruas da capital como uma atividade de lazer paralela a passar o final de semana caçando animais silvestres na floresta. A única exceção, onde alguma medida de homossexualidade parecia sobreviver no domínio público, era dentro dos aspectos mais prestigiados e relacionados com a arte do Carnaval e das mascaradas de Carnaval.

O que ficou claro no trabalho de campo sobre a Internet não foi só o fato de que as condições estavam mudando, mas que a Internet, ela mesma, havia se tornado instrumental em tal mudança. De novo, isso era parcialmente evidente antes de visitar Trinidad. Dois websites, que haviam sido encontrados, se proclamavam como o portão de entrada à cena gay em Trinidad e, assim, assumiram a idéia de ser um gay trinitino em uma expressão e identificação pública, ao que não havia qualquer precedente equivalente. Ao estudar o uso feito dos cibercafés, nós também notamos a importância da ordem espacial dos próprios cafés (algo discutido em mais detalhe em 
Miller; Slater, 2000; veja também Wakeford, 1999). No caso do Chatters, que consistia em uma série de espaços muito divididos entre si, quanto mais ao fundo da área, mais os usuários se sentiam seguros em usar a Internet para fins mais privados, como a pornografia. Mas um grupo específico de usuários regulares usava a sala mais ao fundo do cibercafé como um cenário social para a navegação coletiva na pornografia gay por homens gays. Nesse caso, navegar por pornografia não era uma atividade privada, mas muito mais um evento grupal. Dessa forma, eles conseguiam desenvolver uma presença relativamente pública e participar de uma atividade como um grupo que nunca antes havia saído do domínio privado. No mesmo cibercafé, uma mulher que sentia que ela estava sendo perseguida (através de vírus on-line, etc.) por uma lésbica, cujos avanços ela já havia rejeitado, tendia a envolver a maior parte dos outros freqüentadores na discussão de seu pleito. Assim, a Internet, com a virtude de permitir uma troca privada mais aberta, foi instrumental também para a criação das condições para um emergir tentativo em um domínio mais público daquilo que havia sido uma forma geralmente escondida das relações sociais.

O que é verdade para a sociedade gay parece servir para a maior parte das áreas de atividade social. Para cada nova forma de troca social e forma social que era desenvolvida on-line, como o namoro internacional, trocas baseadas em cartões de egreeting, assinatura recíproca de livros de visita nos websites pessoais, havia também trocas que ocorriam no mundo de relacionamentos off-line. Os cibercafés eram particularmente instrutivos, assim como também eram lugares de encontro para mundos off-line e online. Assim, quando alguém de repente aparecia devastado ou exultante com alguma nova virada em um relacionamento-chave, nunca se podia saber se isso era em decorrência de algo novo que havia aparecido na tela ou algo que alguém havia dito na sala ao lado. Nesse sentido era a imprevisibilidade e a inovação que eram encontradas nas atividades off-line que se apropriavam das possibilidades do cibercafé e faziam deles o que eram. Em um caso, um cibercafé descobriu que havia sido virtualmente tomado por um grupo visitante de estudantes venezuelanos que estavam em Trinidad para melhorar seu inglês e vieram em grupos para "navegar" e fazer contato com seu país, e, então, o espaço se tornou, com efeito, uma casa distante de casa para os venezuelanos. Em outro caso, um cibercafé, que havia sido instalado dentro de um grande shopping center, descobriu que, apesar de sua relutância inicial em assumir esse papel, havia se tornado uma creche efetiva para os

Horizontes Antropológicos, Porto Alegre, ano 10, n. 21, p. 41-65, jan./jun. 2004 
pais que estavam fazendo compras no shopping e que deixavam seus filhos por uma hora ou duas para jogar on-line no cibercafé. Estes não eram reflexos das intenções dos donos ou gerentes dos cibercafés, mas formas em que grupos específicos de consumidores colonizam o potencial das instituições uma vez que elas tenham sido estabelecidas.

\section{Etnografia e cibercafés}

Poderia haver uma tentação para nós, enquanto pesquisadores, de tratarmos os cibercafés como uma forma fácil de constituir nossa pesquisa sobre a Internet como uma etnografia. Eles se conformam a um senso do espaço etnográfico como um local fisicamente delimitado. Eles também respondem a uma necessidade metodológica de encontrar fenômenos da Internet na forma de interações visíveis e, portanto, observáveis. Ademais, eles parecem marcar um ponto óbvio no qual o comportamento on-line pode ser claramente observado de uma perspectiva e um contexto off-line. $\mathrm{O}$ último ponto também se relaciona a uma premissa comum, a de que "contextualizar" o ciberespaço significa simplesmente observar o espaço físico imediato em frente à tela do usuário, como se a etnografia equivalesse simplesmente à fisicalidade. Isso é obviamente fácil demais: estar off-line não significa automaticamente que se está fazendo uma etnografia, nem estar on-line significa que não se está fazendo uma etnografia. Novamente, a questão é uma escolha metodológica sobre o que constitui o "contexto", uma decisão que só pode ser feita no contexto dos objetivos específicos de uma pesquisa. No nosso caso, os cibercafés dificilmente "solucionaram" os problemas etnográficos que encontramos. $\mathrm{E}$, em qualquer caso, eles próprios tinham que ser contextualizados numa escala maior, sobretudo ao recorrer a um levantamento de porta em porta que poderia situar o que nós observamos em relação a padrões muito mais amplos de uso e não uso. De fato, longe de ser uma solução fácil, o objetivo deste artigo foi mostrar que tanto os cibercafés quanto o uso da Internet são termos variáveis e nenhum deles pode ser tratado como o contexto dado e estável para o outro. Isso constituiu o problema para a etnografia, mas também o problema com que só a etnografia poderia lidar. 


\section{Referências}

CLIFFORD, J. Routes. Berkeley: University of California Press, 1997.

GEERTZ, C. The Interpretation of Cultures. New York: Basic Books, 1973.

GUPTA, A.; FERGUSON, J. Discipline and Practice: the "Field" as site, method and location in Anthropology. In: GUPTA, A.; FERGUSON, J. (Ed.). Anthropological Locations. Berkeley: University of California Press, 1997. p. 1-46.

HAKKEN, D.Cyborgs@cyberspace?: an ethnographer looks to the future. London: Routledge, 1999.

HINE, C. Virtual Ethnography. London: Sage, 2000.

LATOUR, B. Aramis, or the Love of Technology. Cambridge: Harvard University Press, 1996.

LIFF, S.; STEWARD, F.; WATTS, P. Public Access to the Internet: New approaches from Internet Cafes and Community Technology Centres and their implications for Libraries. New Review of Information Networking, v. 5, p. 27-41, 1999.

LIFF, S.; STEWARD, F.; WATTS, P. New Public Places for internet access: Networks for practice-based learning and social inclusion. In: WOOLGAR, S. (Ed.). Virtual Society? Oxford: Oxford University Press, 2002. p. 78-98. MARCUS, G. Ethnography In/Of the World System: The emergence of multi-sited ethnography. Annual Review of Anthropology, v. 24, p. 95-117, 1995.

MARCUS, G. Ethnography Through Thick and Thin. Princeton: Princeton University Press, 1998.

MARKHAM, A. Life On-line. New York: Sage, 1998.

McGUIGAN, J. Cultural Populism. London, Routledge, 1992.

MILLER, D. Material Culture and Mass Consumption. Oxford: Basil Blackwell, 1987.

MILLER, D. Modernity: an ethnographic approach. Oxford: Berg, 1994.

MILLER, D. Capitalism: an ethnographic approach. Oxford: Berg, 1997. 
MILLER, D.; SLATER, D. The Internet: an ethnographic approach. Oxford: Berg, 2000.

PACCAGNELLA, L. Getting the seats of your pants dirty: strategies for ethnographic research on virtual communities. Journal of Computer Mediated Communication, v. 3, 1997. Disponível em: <http:// jcmc.huji.ac.il >.

RAO, M. Bringing the Net to the Masses: Cybercafes in Latin America. Cybersociology, v. 4, 22 Apr. 1999. Disponível em: <http:// www.cybersoc.com/magazine $>$.

SILVERMAN, D. Interpreting Qualitative Data: Methods for Analysing Talk, Text and Interaction. London: Sage, 1995.

SLATER, D. Trading Sexpics on IRC: Embodiment and Authenticity on the Internet. Body and Society, v. 4, p. 91-117, 1998.

STRATHERN, M. Property, Substance and Effect: Anthropological Essays on Persons and Things. London: Athlone Press, 1999.

WAKEFORD, N. Gender and the landscapes of computing in an internet café. In: CRANG, M.; CRANG, P.; MAY, J. (Ed.). Virtual Geographies. London: Routledge, 1999. p. 178-201. 